\title{
Stimulus suffixes and visual presentation
}

\author{
ROBERT L. GREENE \\ Case Western Reserve University, Cleveland, Ohio
}

\begin{abstract}
Seven experiments studied whether irrelevant visual stimuli (stimulus suffixes) would interfere with immediate serial recall of supraspan lists of digits presented visually. Across experiments a wide number of conditions were run, varying in method of presentation (sequential or simultaneous), rate of list presentation, and presence or absence of articulatory suppression. In no condition did a visual suffix have a significant detrimental effect on recall. These results stand in marked contrast to those found when auditory lists and suffixes have been used.
\end{abstract}

People are constantly being buffeted by stimuli. Some stimuli are worth remembering, whereas others can safely be forgotten. One of the goals of memory research should be to explain how it is that we are able to remember some events while filtering out others.

One procedure that captures this process is the stimulussuffix paradigm. In this paradigm, a list of items is presented, followed by an irrelevant stimulus that subjects do not have to report. Subjects then try to recall the list. Experiments of this type are meant to discover the circumstances under which people are able to disregard the irrelevant stimulus (the suffix) and prevent it from interfering with their recall of the items.

This paradigm has been studied quite heavily in the auditory modality. Auditory suffixes can cause extensive interference with recall of the list, expecially the last few items (Crowder, 1967; Dallett, 1965). Although auditory suffixes have usually been studied using spoken material, they also can be found in recall of nonspeech auditory stimuli (Greene \& Samuel, 1986). The amount of interference caused by a suffix is typically a direct function of the physical similarity of the suffix to the list items (Morton, Crowder, \& Prussin, 1971). However, situations can be found in which the semantic properties of a suffix influence its effectiveness (e.g., Ayres, Jonides, Reitman, Egan, \& Howard, 1979; Greene, 1985; Salter \& Colley, 1977).

The stimulus-suffix paradigm has been studied relatively little in the visual modality. Several investigators have examined visual suffix effects with procedures that were intended to resemble those used to study auditory suffix effects. Sequential presentation of list items was used. The results have been inconsistent. Hitch (1975) found small, but significant, visual suffix effects that were largest on the last serial position. However, across two experiments, Engle (1974) found no evidence that visual suffixes interfered at all with terminal items.

I am indebted to Jon Thomas for testing subjects in Experiments 6 and 7. Correspondence concerning this article should be addressed to Robert L. Greene, Department of Psychology, Case Western Reserve University, Cleveland, OH 44106.
Several other investigators have used simultaneous presentation of the list items to study visual suffix effects. The earliest studies were those of Kahneman and his colleagues (Kahneman, 1973; Kahneman \& Henik, 1977, 1981). In these experiments, all list items were displayed simultaneously for $200 \mathrm{msec}$, either with or without a suffix appended at the end. Subjects were then to report the list items. Suffixes greatly affected report of the items. However, it may be misleading to consider this a memory phenomenon. Since the list was shown for only $200 \mathrm{msec}$, the subjects may not have had time to identify all of the items in the list. Subjects presumably wasted resources on the identification of the suffix, resources that would be used to identify the list items in the no-suffix condition. Evidence that identification of the items was difficult comes from the fact that lists of only six items were often used and yet performance was far from perfect. Six items should have been well within the immediate memory span of the college students used as subjects.

It should be noted that interference with identification processes is not an adequate explanation for the auditory suffix effect. These auditory experiments typically used sequential presentation and rarely used presentation rates greater than two items per second. Moreover, auditory suffix effects have been found even when suffixes occurred as long as $20 \mathrm{sec}$ after the last item (Watkins \& Todres, 1980). Clearly, all of the list items were identified before the occurrence of the suffix. This effect could truly be considered one of memory, that is, a phenomenon occurring at a stage logically following the completion of perceptual identification.

In a pair of studies that were published after the present set of experiments was completed, Frick and DeRose (1986a, 1986b) used a somewhat different approach. Rather than using immediate serial recall of lists composed of a fixed number of items, they used a memory span task. Span capacity was determined by the up-down method. When the subject recalled all of the items in the list correctly, list length was increased by one. When the subject was not able to recall the entire list correctly, list length was decreased by one. Memory span was calculated as the average number of items in the lists. Items were presented simultaneously for a total of $560 \mathrm{msec} \times$ 
the number of items. Subjects were required to engage in articulatory suppression during list presentation. Frick and DeRose found that memory span was decreased if a suffix was appended to the end of the list.

Since Frick and DeRose (1986a, 1986b) replicated their findings several times, the reliability of the visual suffix effect in their paradigm does not seem open to question. However, one may hesitate before generalizing their findings to other paradigms. The methodology that Frick and DeRose employed was extremely different from that used by previous investigators of either visual or auditory suffix effects. The suffix effect is typically defined as a selective impairment on recall of terminal items. Since no serial-position curves could be reported using the Frick and DeRose procedure, it was not clear that their findings correponded to the expected pattern. Also, the updown procedure may not be the optimal way to study suffix effects. When the up-down procedure is used, list length varies from one trial to the next. The seventh stimulus presented may be a list item on one trial and an irrelevant suffix on the next. Subjects have no way of knowing whether to report an item without keeping count or analyzing the suffix for meaning. In contrast, previous investigators used a fixed list length over the course of the experiment, and this might have helped the subject not to confuse the suffix with list items. Finally, it is not clear if one can generalize from span experiments to experiments using supraspan lists. As Watkins (1977) noted, span is typically defined as "the length of a list for which there is an even chance of perfect recall" (p. 529). Supraspan lists would therefore be of a length greater than this (e.g., if the list is composed of digits, list length would have to be greater than seven). Although it is clear that recall of multispan lists uses several distinct processes (Greene, 1986), it has sometimes been argued that recall of span lists involves predominantly only one process (e.g., Cavanaugh, 1972; Schweickert \& Boruff, 1986). It may not be possible to generalize from one procedure to the other.

This series of experiments was carried out to determine whether suffix effects are found with visual presentation of supraspan lists. To ensure that identification would be no problem, the first three experiments used sequential presentation. The next four experiments used simultaneous presentation but allowed sufficient time for identification of the stimuli. Immediate serial recall of supraspan lists was used to avoid the interpretive problems that arise with the up-down method of memory span and to allow comparison with previous experiments on the auditory suffix effect.

\section{EXPERIMENT 1}

When auditory presentation is used, recall is hurt by a speech suffix but not by a nonspeech suffix. This experiment determined whether recall of digits presented in graphic form exhibits similar patterns. Lists of digits were followed either by another meaningful graphic symbol (a zero) or by an asterisk.

\section{Method}

Subjects. Eighteen students from introductory psychology classes at Case Western Reserve University participated for course credit and were tested individually.

Procedure. The subjects received 64 lists. Each list was composed of the digits 1 through 9 , arranged in random order, with each digit occurring once on a list. The lists were shown on a terminal controlled by an Apple Ile computer system. The items were shown one at a time in the upper left corner of the terminal screen at a rate of two items per second. The subjects were instructed to read each item silently. Each list was followed either by an asterisk or by the digit zero. The subjects were required to keep their gaze on the terminal while the suffix was displayed. (The experimenter monitored compliance.) The suffix went off the screen after half a second, and the subjects recalled the list orally. They were required to recall the items in order and to guess if they were uncertain at a particular position.

The arrangement of lists followed by asterisks and zeros was random, with the constraint that 2 lists of each kind occurred in the first 4 lists and that 30 lists of each kind occurred in the next 60 lists. The first 4 lists were considered practice and were not scored.

\section{Results and Discussion}

All analyses reported here used a criterion of .05 probability of Type 1 error to define statistical significance.

The results from Experiment 1 are displayed in Figure 1 . There was no sign of any difference at all between the two kinds of suffix. There was a main effect of serial position $[F(8,136)=57.26, M S e=15.30]$, but neither the main effect of suffix condition nor the interaction of suffix with position approached significance (in both cases, $F<1.0$ ).

It is possible that the failure to find a suffix effect in Experiment 1 was the result of a faulty choice of control condition. The asterisk used as a control here may itself have been an effective suffix. Therefore, a different control condition was used in Experiment 2.

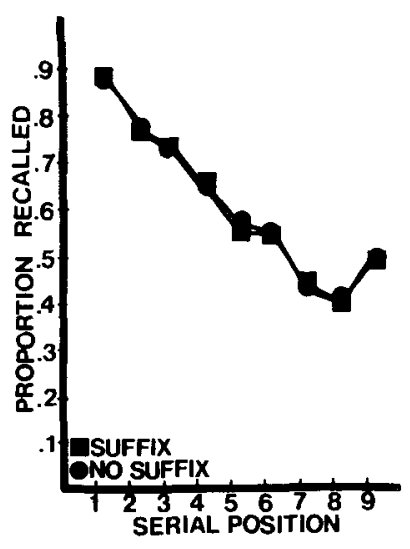

Figure 1. Mean proportion of items recalled in Experiment 1 as a function of condition (suffix or control) and serial position. 


\section{EXPERIMENT 2}

\section{Method}

Subjects. Sixteen students from introductory psychology classes at Case Western Reserve University participated for course credit.

Procedure. The procedure used was the same as for Experiment 1 , with one exception. Rather than using an asterisk in the control condition, the screen simply went blank after the last item in the control condition. A zero was again used as the suffix.

\section{Results and Discussion}

The results are shown in Figure 2. Once again, the suffix clearly had no effect. Although the main effect of position was easily significant $[F(8,120)=40.09, M S \mathrm{e}$ $=23.28 \mathrm{~J}$, both the main effect of suffix condition and the interaction of this variable with position again failed to approach significance (in both cases, $F<1.0$ ). The results of this experiment fail to replicate Hitch's (1975) finding of significant visual suffix effects under similar conditions. Instead, the results more closely parallel those of Engle (1974).

The first two experiments followed the procedure typically employed in suffix studies by always having the suffix follow the terminal list item. However, if the broader purpose of these studies was to determine the circumstances under which people are able to prevent interference from irrelevant stimuli, there was no reason at all to keep suffixes only at the end of the list. In Experiment 3 , a much wider variety of conditions was employed.

\section{EXPERIMENT 3}

\section{Method}

Subjects. Forty-three students from introductory psychology classes at Case Western Reserve University participated for course credit.

Procedure. As in Experiments 1 and 2, the subjects received lists of random orderings of the digits 1 through 9 , presented on a computer terminal screen at a rate of two items per second. Half of the lists contained a suffix (the digit 0 ) presented in rhythm with the list items. However, unlike the first two experiments, the suffix

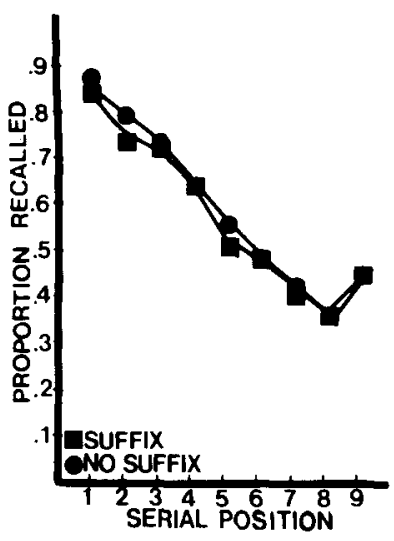

Figure 2. Mean proportion of items recalled in Experiment 2 as a function of condition (suffix or control) and serial position.
Table 1

Mean Proportion Correct in Experiment 3 on Lists Containing a Pause

\begin{tabular}{cccccccccc}
\hline & \multicolumn{10}{c}{$\begin{array}{c}\text { Serial Position } \\
\text { Position }\end{array}$} & 1 & 2 & 3 & 4 & 5 & 6 & 7 & 8 & 9 \\
\hline 1 & .91 & .80 & .75 & .67 & .61 & .56 & .49 & .38 & .47 \\
2 & .93 & .83 & .77 & .60 & .58 & .54 & .47 & .41 & .56 \\
3 & .91 & .79 & .74 & .70 & .56 & .56 & .50 & .42 & .53 \\
4 & .91 & .81 & .86 & .66 & .66 & .67 & .46 & .37 & .46 \\
5 & .90 & .76 & .79 & .68 & .58 & .58 & .46 & .42 & .51 \\
6 & .95 & .77 & .75 & .70 & .61 & .55 & .43 & .41 & .50 \\
7 & .88 & .76 & .77 & .58 & .56 & .60 & .49 & .43 & .54 \\
8 & .92 & .71 & .62 & .51 & .54 & .52 & .50 & .40 & .52 \\
9 & .87 & .73 & .72 & .58 & .46 & .57 & .44 & .45 & .56 \\
10 & .90 & .78 & .74 & .70 & .60 & .60 & .48 & .41 & .56 \\
\hline
\end{tabular}

Table 2

Mean Proportion Correct in Experiment 3 on Lists Containing a Sufnxx

\begin{tabular}{cccccccccc}
\hline & \multicolumn{10}{c}{ Serial Position } \\
\cline { 2 - 10 } Suffix & & & \multicolumn{10}{c}{} & \\
Position & 1 & 2 & 3 & 4 & 5 & 6 & 7 & 8 & 9 \\
\hline 1 & .94 & .81 & .78 & .63 & .59 & .58 & .47 & .39 & .50 \\
2 & .93 & .87 & .77 & .63 & .62 & .63 & .50 & .41 & .56 \\
3 & .90 & .82 & .72 & .52 & .51 & .54 & .39 & .42 & .48 \\
4 & .87 & .82 & .74 & .62 & .58 & .60 & .55 & .45 & .49 \\
5 & .87 & .77 & .75 & .67 & .52 & .52 & .49 & .48 & .52 \\
6 & .87 & .70 & .73 & .64 & .51 & .58 & .49 & .42 & .55 \\
7 & .91 & .70 & .73 & .69 & .60 & .63 & .52 & .48 & .54 \\
8 & .86 & .70 & .69 & .62 & .54 & .59 & .40 & .45 & .51 \\
9 & .93 & .77 & .75 & .59 & .56 & .52 & .49 & .40 & .55 \\
10 & .87 & .80 & .67 & .58 & .51 & .50 & .44 & .37 & .50 \\
\hline
\end{tabular}

in this case could occur anywhere in a list. It could occur before any of the nine items, as well as after the last one. Only one suffix appeared on any list. In short, there were 10 different suffix conditions.

Suffixes in this experiment would have two possible effects. They would be an interfering stimulus, but they would also interrupt list presentation and influence grouping strategies. To help separate these two possibly conflicting effects, 10 other conditions were included in this study. In these conditions, a pause of $500 \mathrm{msec}$ was inserted in the list. A pause could occur before any of the nine items or after the last item.

Each subject received 80 lists, 4 lists in each of the 20 conditions.

\section{Results and Discussion}

The mean proportions correct for each serial position are shown in Table 1 for those lists in which pauses occurred and in Table 2 for those lists in which suffixes occurred. There were 10 positions in which a pause or a suffix could occur. A pause or a suffix could be inserted before each of the nine items or after the last item. In all, there are 180 different means to be reported from this experiment. Emphasis will be placed on general patterns in the data. An overall analysis of variance was performed using serial position and condition as independent variables. Although position had a significant effect on recall $[F(8,336)=89.31, M S \mathrm{e}=76.18]$, neither the main ef- 
fect of condition nor the interaction of this variable with position approached significance (in both cases, $F<1.0$ ).

Two conditions can be considered control conditions. These are the conditions in which the pause occurs either at Position 1 (before the first item) or at Position 10 (after the last item). The overall proportions recalled in these two conditions were .63 and .64 , respectively. The overall proportions correct in the other 18 conditions ranged from .59 to .66 . No condition differed significantly from the two control conditions when tested in a pairwise fashion.

One can use the means of the control conditions to look more specifically at the effects of pauses and suffixes. For example, to determine if there is any benefit for an item to come immediately after a pause, one can make up a mean of the positions in the nine relevant conditions in which the item immediately follows a pause. This mean is .63. The mean for the nine positions immediately following suffixes is .64. Obviously, these means do not differ from each other or from the means of the control conditions. There is no effect at all for an item to follow immediately either a pause or a suffix.

It is reasonable to look at recall of the items immediately preceding a suffix. The mean of these nine positions is .63 , which obviously does not differ from the mean of the control conditions. The mean for items immediately preceding a pause was .67 , which also was not significantly different from the means of the control conditions.

Dallett (1965) performed an experiment that is an auditory analogue to Experiment 3 . In that experiment, auditory suffixes could occur after any of the items on an auditorily presented list. (That study did not employ pauses, however.) Dallett consistently found large effects of suffixes, no matter where they occurred in the list. Those results stand in marked contrast to the present results, where visual suffixes seem to be ineffective no matter where they appear on the list.

Experiments 1 through 3 employed a sequential method of presentation. Although this is similar to the methods used to study auditory suffixes, it may not be the most appropriate method to use when studying visual suffixes. Kahneman and Henik (1977) argued that simultaneous presentation would be a more natural method to use in the visual modality. Therefore, the rest of the experiments discussed here involved simultaneous presentation of all the items on a list.

\section{EXPERIMENT 4}

\footnotetext{
Method

Subjects. Twenty-one students from introductory psychology classes at Case Western Reserve University participated for course credit and were tested individually.

Procedure. As was the case with Experiments 1 and 2, each subject received 64 lists. The first four lists were considered practice and were not scored. Each list consisted of random orderings of the digits 1 through 9 . Unlike earlier experiments, however, all items on a list were displayed simultaneously across the top line
}

of a terminal screen. To equate overall presentation time with the earlier experiments, each list was shown for $4.5 \mathrm{sec}$.

On half of the lists, a zero was presented as a 10th digit at the same time as the nine list items. On the remaining lists, only the nine items were shown.

\section{Results and Discussion}

The results from Experiment 4 are shown in Figure 3. To repeat what is now a familiar story, there was a significant main effect of serial position $[F(8,160)=40.03$, $M S \mathrm{e}=21.46]$, but neither the main effect of the suffix $[F(1,20)=1.28, M S e=11.30]$, nor the interaction of the suffix with position $[F(8,160)=0.91, M S e=2.58]$, approached significance.

Experiment 4 used a presentation time of $4.5 \mathrm{sec}$ to keep total time constant with the previous experiments reported here. However, it may be unrealistic to expect a suffix effect under these conditions. The subjects reported having enough time to scan the list several times over; therefore control over functional serial position was lost. Ideally, one would want to use a presentation time that would allow time for the subjects to identify all of the items and yet not have time to scan through the list more than once. After testing a number of pilot subjects and asking for their introspections, it seemed as if a total presentation time of $1.2 \mathrm{sec}$ would meet these requirements.

\section{EXPERIMENT 5}

\section{Method}

Subjects. Twenty-two students from introductory psychology classes at Case Western Reserve University participated for course credit.

Procedure. The procedure was identical to that used in Experiment 4, except that a total presentation time of $1.2 \mathrm{sec}$ was used for each list.

\section{Results and Discussion}

The results are shown in Figure 4. The main effect of serial position was again significant $[F(1,21)=69.07$, $M S \mathrm{e}=25.20]$. However, both the suffix effect $[F(1,21)$

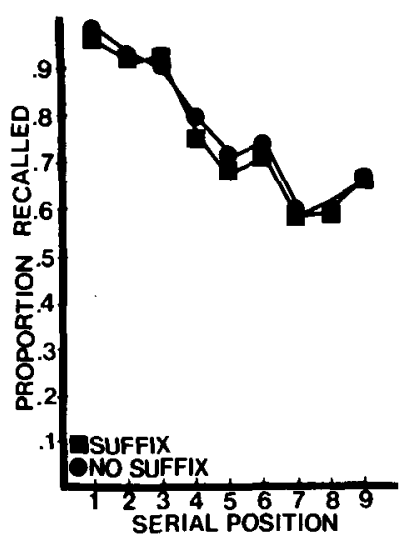

Figure 3. Mean proportion of items recalled in Experiment 4 as a function of condition (suffix or control) and serial position. 


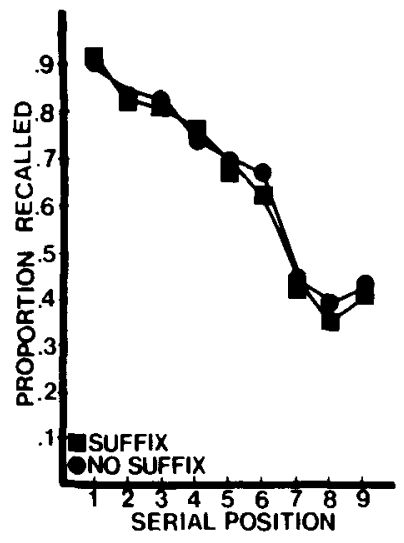

Figure 4. Mean proportion of items recalled in Experiment 5 as a function of condition (suffix or control) and serial position.

$=2.47, M S e=14.23]$ and the interaction of the suffix with serial position $[F(8,168)=0.82, M S e=4.23]$ failed to reach significance.

Clearly, finding a visual suffix effect is considerably more challenging than finding an auditory suffix effect. One reason for this may be that subjects tend to rely on acoustic coding in serial recall tasks of this sort (Conrad, 1964). It may be unrealistic to expect to find visual interference in situations where the stimuli are not coded visually.

Frick (1985) claimed that visual coding is used in immediate memory only when simultaneous presentation is used and subjects are forced to engage in articulatory suppression. Frick and DeRose (1986a, 1986b) used articulatory suppression in their studies on the effects of visual suffixes on memory span. Experiment 6 was intended to discover if visual suffix effects could be found in immediate serial recall of supraspan lists when articulatory suppression was used.

\section{EXPERIMENT 6}

\section{Method}

Subjects. Sixteen students from introductory psychology classes at Case Western Reserve University participated for course credit.

Procedure. This experiment was run in two blocks. The lists in one block were presented in the same way as those used in Experiment 5 . In the other block, the subjects were required to repeat "la, la" as rapidly as possible. The subjects began this articulation before list presentation. When the experimenter was satisfied that the subejct was fully engaged in this activity, the experimenter pressed a key on the terminal to initiate presentation of the list. The subjects were required to maintain this articulatory suppression until after the list had gone off the screen.

The subjects received 28 lists in each of the two blocks. Half of the lists in each block contained a zero suffix appended to the list, but the others did not. The first four lists in each block were considered practice and were not scored. The order of blocks was counterbalanced across subjects.

\section{Results and Discussion}

The results are shown in Figure 5. There was a main effect of articulatory suppression $[F(1,15)=25.32, M S \mathrm{e}$
$=14.63]$, indicating that performance was significantly worse when the subjects were required to engage in suppression. There was also a significant main effect of serial position $[F(8,120)=144.12, M S e=4.39]$. The interaction between articulatory suppression and position was also significant $[F(8,120)=4.08, M S \mathrm{e}=2.28]$. This interaction presumably reflects the fact that suppression had no effect on recall of the initial item on a list. This interaction should be interpreted with caution, however, because it may just reflect a ceiling effect on performance on initial items.

The suffix is of greater theoretical interest. However, the main effect of the suffix and all interactions of other variables with the suffix failed to approach significance (in all cases, $F<1.0$ ).

One troublesome aspect of the results found here is that performance in the articulation condition was quite poor for the last few items. One could legitimately worry that a floor effect might be obscuring the suffix effect in this condition. One way to deal with this concern is to raise the level of performance by shortening list length. This was done in Experiment 7, where a list length of only six items was used. A list this short will obviously lead to near-ceiling performance in the silent control condition. However, it is only the articulation condition that is of theoretical interest, and the presence of articulatory suppression seems to reduce performance to the point that even a list of six items exceeds most subjects' ability to reproduce the series perfectly.

\section{EXPERIMENT 7}

\section{Method}

Subjects. Sixteen students from introductory psychology classes at Case Western Reserve University participated for course credit.

Procedure. The procedure used here was identical to that employed in Experiment 6, with the exception that each list was composed of only six items chosen randomly from the digits 1 through 9. As was the case in Experiment 6, there were two blocks of 28 lists each, with the first four lists in each block considered practice and not scored. Half of the lists in each block had a zero appended

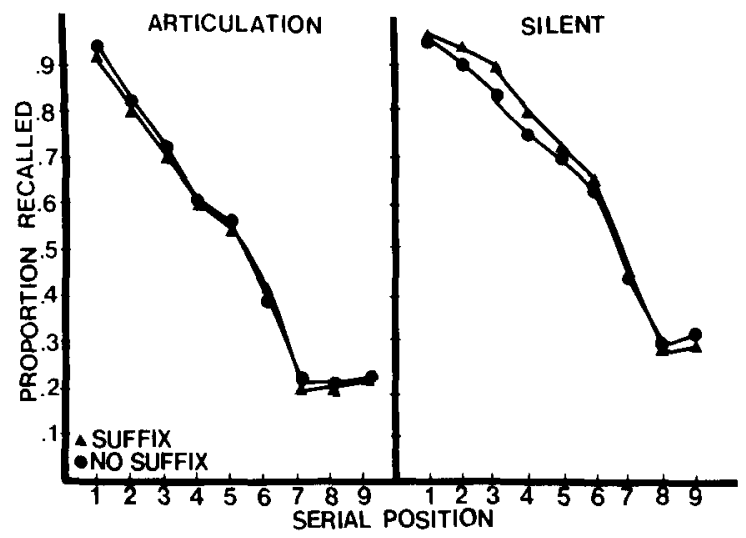

Figure 5. Mean proportion of items recalled in Experiment 6 as a function of presence of articulatory suppression, condition (suffix or control), and serial position. 


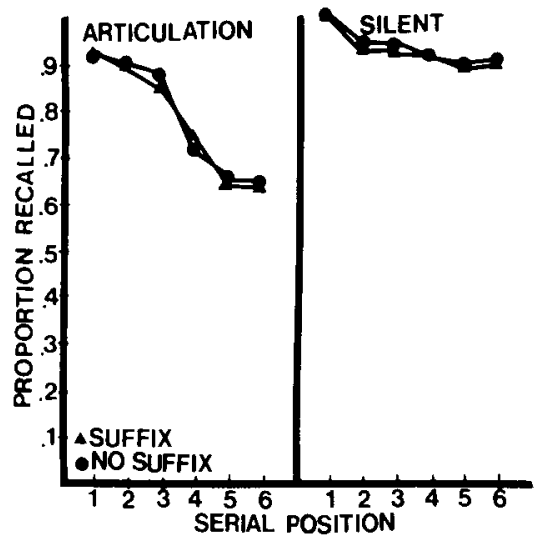

Figure 6. Mean proportion of items recalled in Experiment 7 as a function of presence of articulatory suppression, condition (suffix or control), and serial position.

at the end as a suffix. One block required articulatory suppression, whereas the other was a silent control condition. The order of blocks was counterbalanced across subjects.

\section{Results and Discussion}

The results are shown in Figure 6. The main effects of articulatory suppression $[F(1,15)=46.32, M S e=$ $6.31]$ and serial position were significant $[F(5,75)=$ $20.64, M S e=3.56]$. There was a significant interaction between articulation and position $[F(5,75)=14.62, \mathrm{MSe}$ $=1.57$, which at least partly reflects the fact that performance was near ceiling for all positions in the silent control condition. Of greater importance is the suffix effect. No attempt should be made to interpret the results found in the silent condition, in which the near-ceiling levels of performance reduce the possibility of finding any significant effects. However, there is no sign of a suffix effect even in the articulation condition where performance on the last few items was clearly below the ceiling. The effect of the suffix $[F(1,15)=3.06, M S \mathrm{e}=1.14]$, the interaction between articulation and the suffix $[F(1,15)$ $=0.01, M S e=2.00]$, the interaction between position and the suffix $[F(5,75)=1.93, M S e=0.58]$, and the three-way interaction among the suffix, articulation, and position $[F(5,75)=1.60, M S \mathrm{e}=0.98]$ all failed to reach significance.

\section{GENERAL DISCUSSION}

The stimulus-suffix paradigm tests whether subjects are able to prevent irrelevant stimulation from interfering with information they are trying to remember. The experiments discussed above all lead to the conclusion that people are very good at this when visual presentation of supraspan lists is used. Since these experiments involve accepting the null hypothesis, one should hesitate before concluding that visual suffixes have absolutely no effect under the conditions studied here. However, it seems fair to conclude that visual suffixes do not cause massive interference of the sort found when auditory supraspan lists and suffixes are used.
In these experiments, visual presentation of digits was employed. There is evidence that these conclusions may hold when other sorts of visual stimuli are used. Phillips and Christie (1977) tested memory for short lists of novel abstract patterns. The subjects seemed to rely on visual coding of the stimuli, particularly the last item on a list. However, the mere presentation of a similar pattern immediately after the last item caused no interference with memory. These results agree with those found here by suggesting that mere presentation of a visual suffix is not sufficient to interfere with visually presented items. Also, they are in agreement with the results from Experiments 6 and 7 in suggesting that visual coding is not a sufficient condition for the presence of visual suffix effects.

Since there have been reports of visual suffix effects using other procedures (Frick \& DeRose, 1986a, 1986b; Kahneman \& Henik, 1977, 1981), one should not conclude that visual suffixes are never effective. However, when procedures are used that are similar to those used to study auditory suffix effects, substantial visual suffix effects are not found.

The great difference between the effects of auditory and visual suffixes suggests that there is an additional source of information that is used only to recall auditory information but that is not available for recall of visual information. This additional source of information is responsible for the large auditory advantage in immediate recall (the modality effect; see Conrad \& Hull, 1968; Corballis, 1966; Crowder \& Morton, 1969; Murray, 1966). However, this information is extremely susceptible to interference from subsequent auditory stimulation.

Unfortunately, it is not at all clear what this additional source of information is. Several years ago, one could claim that it was echoic (auditory sensory) memory. According to this account, information in echoic memory persisted for a long enough time to allow subjects to use it when recalling the last item on a list unless a suffix occurred that served as a mask (Crowder \& Morton, 1969). Iconic (visual sensory) memory would decay too rapidly to be of help in recall tasks of this sort. This theory was able to account for the modality effect as well as the auditory suffix effect, but it no longer seems to be a tenable explanation for either phenomenon (for reviews, see Gardiner, 1983; Greene, 1986). One piece of evidence against it is that there is at least one type of visual presentation that can lead to sizable suffix effects. When subjects have to lip-read list items, their recall can be greatly disrupted by either auditory or lip-read suffixes (Greene \& Crowder, 1984). Lipreading in general leads to patterns of recall more similar to those found with auditory presentation than to those found with other sorts of visual presentation (Campbell \& Dodd, 1980; Spoehr \& Corin, 1978). As a result of findings such as these, the echoicmemory account has been disproven, and no alternative has been proposed that is capable of explaining the whole range of phenomena once accomodated by this theory (Crowder, 1986; Greene \& Crowder, 1986).

Several authors (Hitch, 1975; Kahneman \& Henik, 1977,1981 ) have commented on the similarity between 
visual and auditory suffix effects and have suggested that this similarity should be a starting point for theories of the suffix effect. The results found here argue for exactly the opposite approach. Visual and auditory suffixes differ tremendously in their effects, and any theoretical account of suffix effects should take this fundamental difference as a starting point.

\section{REFERENCES}

Ayres, T. J., Jonides, J., Reitman, J. S., Egan, J. C., \& Howard, D. A. (1979). Differing suffix effects for the same physical suffix. Journal of Experimental Psychology: Human Learning \& Memory, 5, 315-321.

CAMPBELl, R., \& DoDD, B. (1980). Hearing by eye. Quarterly Journal of Experimental Psychology, 21, 450-461.

Cavanaugh, J. P. (1972). Relation between the immediate memory span and the memory search rate. Psychological Review, 79, 525-530.

ConRad, R. (1964). Acoustic confusions in immediate memory. British Journal of Psychology, 55, 75-84.

Conrad, R., \& Hull, A. J. (1968). Input modality and the serial position curve in short-term memory. Psychonomic Science, 10, 135-136.

Corballis, M. C. (1966). Rehearsal and decay in immediate recall of visually and aurally presented items. Canadian Journal of Psychol. ogy, 20, 43-51.

Crowder, R. G. (1967). Prefix effects in immediate memory. Canadian Journal of Psychology, 21, 268-275.

Crowder, R. G. (1986). Auditory and temporal factors in the modality effect. Journal of Experimental Psychology: Learning, Memory, \& Cognition, 12, 268-275.

Crowder, R. G., \& MorTon, J. (1969). Precategorical acoustic storage (PAS). Perception \& Psychophysics, 5, 365-373.

DALletT, K. M. (1965). "Primary memory": The effects of redundancy upon digit repetition. Psychonomic Science, 3, 237-238.

ENGLE, R. W. (1974). The modality effect: Is precategorical acoustic storage responsible? Journal of Experimental Psychology, 102, 824-829.

FRICK, R. W. (1985). Testing visual short-term memory: Simultaneous versus sequential presentation. Memory \& Cognition, 13, 346-356

FrICK, R. W., \& DeRose, A. (1986a). Attenuating the visual suffix effect with color. Memory \& Cognition, 14, 391-397.

Frick, R. W., \& DeRose, A. (1986b). The suffix effect and preattentive unit-formation in visual short-term memory. Canadian Journal of Psychology, 40, 97-108.

Gardiner, J. M. (1983). On recency and echoic memory. Philosophical Transactions of the Royal Society of London, B 302, 267-282.
Greene, R. L. (1985). Constraints on the long-term modality effect. Journal of Memory \& Language, 24, 526-541.

Greene, R. L. (1986). Sources of recency effects in free recall. Psychological Bulletin, 99, 221-228.

Greene, R. L., \& Crowder, R. G. (1984). Modality and suffix effects in the absence of auditory stimulation. Joumal of Verbal Learning \& Verbal Behavior, 23, 371-382.

Greene, R. L., \& Crowder, R. G. (1986). Recency effects in delayed recall of mouthed stimuli. Memory \& Cognition, 14, 355-360.

Greene, R. L., \& Samuel, A. G. (1986). Recency and suffix effects in serial recall of musical stimuli. Journal of Experimental Psychology: Learning, Memory, \& Cognition, 12, 517-524.

Hitch, G. J. (1975). The role of attention in visual and auditory suffix effects. Memory \& Cognition, 3, 501-505.

Kahneman, D. (1973). Attention and effort. Englewood Cliffs, NJ: Prentice-Hall.

Kahneman, D., \& HeniK, A. (1977). Effects of visual grouping on immediate recall and selective attention. In S. Dornic (Ed.), Attention and performance VI. Hillsdale, NJ: Erlbaum.

Kahneman, D., \& HeNIK, A. (1981). Perceptual organization and attention. In M. Kubovy \& J. Pomerantz (Eds.) Perceptual organization. Hillsdale, NJ: Erlbaum.

Morton, J., Crowder, R. G., \& Prussin, H. A. (1971). Experiments with the stimulus suffix effect. Journal of Experimental Psychology, 91, 169-190.

Murray, D. J. (1966). Vocalization-at-presentation and immediate recall, with varying recall methods. Quarterly Journal of Experimental Psychology, 18, 9-18.

Philliss, W. A., \& Christie, D. F. M. (1977). Interference with visualization. Quarterly Journal of Experimental Psychology, 29, 637-650.

Salter, D., \& Colley, J. G. (1977). The stimulus suffix effect: A paradoxical effect. Memory \& Cognition, 5, 257-262.

SCHWEICKERT, R., \& BORUFF, B. (1986). Short-term memory capacity: Magic number or magic spell? Journal of Experimental Psychology: Learning, Memory, \& Cognition, 12, 419-425.

SPOEhr, K. T., \& CoRIN, W. J. (1978). The stimulus suffix effect as a memory coding phenomenon. Memory \& Cognition, 6, 583-589.

WATkins, M. J. (1977). The intricacy of memory span. Memory \& Cognition, 5, 529-534.

Watkins, M. J., \& Todres, A. K. (1980). Suffix effects manifest and concealed: Further evidence for a 20-second echo. Journal of Verbal Learning \& Verbal Behavior, 19, 46-53.

(Manuscript received November 20, 1986; revision accepted for publication February 5, 1987.) 